\title{
Inspiring radiographers to engage in research
}

\section{Guest Editorial}

The value which research brings to health and wellbeing is unquestioned. Without it, progress in diagnosis, treatment and care would probably cease and the service offered to patients and clients would deteriorate. Engaging student radiographers, and radiographers who are early in their careers, with the research agenda is important as it is this group of people particularly who could go on to make meaningful career-long contributions to the radiographic knowledge base and clinical practice advancements. The radiography profession continues to suffer from a lack of engagement in research and because of this, in 2012, a multi-national collaboration was established to create a residential summer school in order to provide a real research experience to inspire participants to value research and/or carry out research as part of their career. The summer school is called OPTIMAX and it is primarily aimed at BSc student radiographers. MSc students and newly qualified radiographers are welcome to participate; also, university tutors are also welcome too as they can gain greatly from it. For doctoral (e.g. PhD) qualified radiographers, attending OPTIMAX iscould be a good steppingstone in researchin a post-doctoral career as it offers a good experience in team working in research., because we know that many of these people only hold the qualification but do not do research. It is worth remembering that a doctoral qualification is solely intended to develop research abilities and the research career should start on the day the doctoral qualification is acquired. Sadly, for many individuals within radiography, the day the doctoral qualification is attained is the day research stops. OPTIMAX therefore offers an opportunity to a wide range of people, to inspire and help them gain skills, confidence and insight into how research can be conducted in teams and disseminated for the benefit of others.

OPTIMAX is a 3-week duration multi-national / multi-professional summer school that comprises 20 consecutive days of structured activities for tutors and students. It first ran in 2013 and in 2019 the $7^{\text {th }}$ rendition was held at the University of Salford._-The journal article outputs from OPTIMAX 2019 are included in this special issue $\begin{array}{llll}1 & 3 & 4 & 5\end{array}$. OPTIMAX offers participants a chance to work in a multi-national research team on laboratory-based research projects, from conception to publication. To achieve this an effective research environment is created by the host university to facilitate each research team to complete their research tasks and to achieve outcomes in the short timeframe of 20 days. It is very intensive. 
It is worth noting that an effective research environment is one where adequate physical and human resource are in place to deliver research ambitions and the research itself is organised in a way that makes effective use of equipment and people's time through good quality team working. Furthermore, it is one in which research is valued and any cultural differences between researchers are respected. An effective environment therefore seeks to support research in a vibrant and sustainable fashion.

Nine months prior to OPTIMAX summer school commencement, a multi-national steering committee starts to meet monthly to ensure everything is in place. This includes finance for conducting the research and the costs associated with personal expenses, such as flights, accommodation and subsistence. Research questions are agreed in advance along with outline methods. Using this information, the physical resource necessary can be identified for conducting the research. In advance, Health and Safety is assured, through compliance with legislation and guidance and this includes quality testing of machinery and ensuring that participants have read and comply with local rules (e.g. radiation safety). At summer school commencement, participants are assigned into one multi-national research team, of size 610 people. The maximum number of students on a summer school is 50 , minimum 25 . The smallest number of tutors is 7, one for each research team (usually 6 teams) from the participating Universities and one senior staff member is in overall charge of OPTIMAX from the host university. Normally there are around 20 tutors involved, with 7 being present full time for all 20 days and the remainder being involved for 1 -week time periods. For the latter it is often a valuable learning experience for them. If you wish to create an experience similar to OPTIMAX please consider reading 'How to create your own OPTIMAX ${ }^{6}$ ' and follow the flowchart steps (Figure 1). External grant funding could be essential in the early 1-2 years to ensure sustainability can be achieved thereafter, in which partner organisations may provide a level of financial subsidy (e.g. through small financial awards to participants and provision of resources for free when organising it within their own institution). It is worth noting that creating and organising OPTIMAX is a major undertaking. It requires a lot of time and dedication.

Figure 1. Flow chart steps on how to start, develop and make sustainable a project using the same model as OPTIMAX

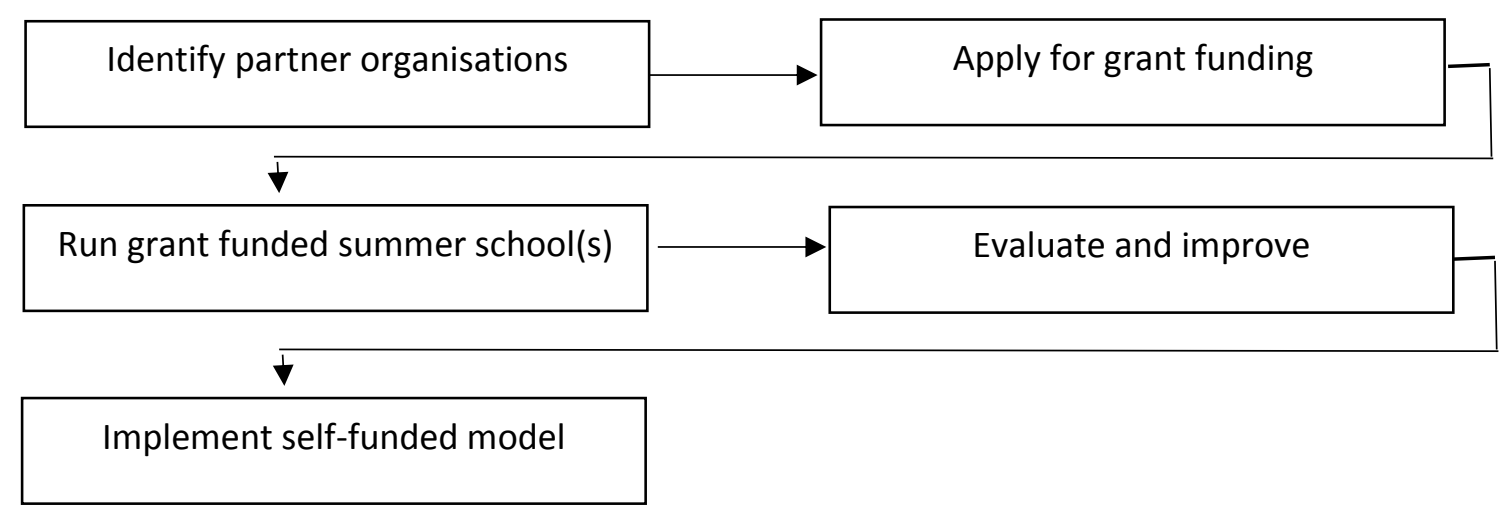



FDuring OPTIMAX, tutors and students participate on an equal first name basis, though one tutor is [nominally] the lead for each team. Team skills and project management, in theory and practice, are learnt throughout the first two days of the summer school so that people can work efficiently together in teams to manage their project through to conclusion. Throughout the 20-day summer school, the senior academic staff member who is in control of the whole OPTIMAX environment meets with all tutors every 2 days to make sure everything is going as planned. If a problem is encountered, then it is solved immediately and usually within 1-2 hours of it arising. The environment is highly responsive and agile. Prior to summer school commencement, participants must have minimum ability levels in research (e.g. structured literature searching) and they must be able to converse adequately in English, both spoken and written - English is the universal language of OPTIMAX. After concluding the initial two days of training, students and tutors conduct research in their teams. This involves searching and critiquing literature, clarifying and validating methods, collecting and analysing data and producing a conference poster and draft journal article by the final day. On the final day each research project is presented in the OPTIMAX conference. After the final day of the summer school, the draft articles are developed further and submitted to a journal for publication (e.g. $789{ }^{10}$ ) or published in an online book (e.g. ${ }^{11} 121314{ }^{15}$ ) as well as being presented at an international conference (typically European Congress of Radiology). All tutors and students are listed as co-authors, as they comply with international guidelines $\left({ }^{16}\right)$.

It is worth remembering that BSc and MSc projects offer students a chance to develop a small piece of research, often in isolation fromef others but with input from an academic supervisor. Whilst such projects are a good opportunity for developing research skills, they are often limited in their ability to confer a holistic research experience, for example, teams are the norm for conducting research and dissemination through journals and conferences would routinely be an outcome on the way to implementing findings into practice. Similarly, for PhD work, the student often works within a small supervisory team and once again, depending upon the route taken, a range of experiences and skills can be lacking - e.g. working in a team of peers. OPTIMAX addresses these deficiencies, as publication and conferences papers are an expected outcome and the research is conducted in teams.

OPTIMAX has run for 7 consecutive years and many of the student participants have gone into career pathways that involve research. For some, research is a small part of their job. For others, research has become a primary focus and they have already completed $\mathrm{PhD}$ qualifications with a view to conducting research in clinical teams. Reflecting on our 2019 summer school experience, once again many student participants were keen to see their career evolve with research featuring as an important component of it.

The steering committee of OPTIMAX is keen to consider the inclusion of 'translating research findings into practice'. Presently, our thoughts on this are rudimentary but given the rapidly increasing importance of translating researchincreasing importance of translation, we anticipate in theory at least it should be included into OPTIMAX.

We recommend the philosophy of OPTIMAX as a valuable development opportunity and experience for newly qualified radiographers, students at all levels and university tutors. We recommend that similar learning experiences be created to simulate further interest in 
research and the value it can haveprovide to practice. OPTIMAX will run again in 2020 in Gronnigen, Netherlands.

\footnotetext{
${ }^{1}$ To be inserted when it is accepted

2 To be inserted when it is accepted

${ }^{3}$ To be inserted when it is accepted

${ }^{4}$ To be inserted when it is accepted

${ }^{5}$ To be inserted when it is accepted
}

${ }^{6}$ Hogg P, Jorge J, How to create your own OPTIMAX, pages 11-29, in OPTIMAX 2016 - Optimising image quality for medical imaging, Edited by Hogg P, Hogg-Thompson R and Buissink C, ISBN 978-1-907842-93-1, 2017. http://usir.salford.ac.uk/id/eprint/41428/1/OPTIMAX\%202016\%20final\%20version.pdf

${ }^{7}$ Lança L, Francob L, Abdulfatah A, Harderwijkd M, Martib C, Nasirc S, Ndlovuc J, Oliveiraa M, Santiagoa A, Hogg $P, 10 \mathrm{kVp}$ rule - An anthropomorphic pelvis phantom imaging study using a CR system: Impact on image quality and effective dose usingAEC and manual mode, Radiography 20 (2014) 333e338

${ }^{8}$ Reis C, Gonçalvesa J, Klompmakerb C, Barbaraa A, Bloor C, Hegarty R, Lagranged T, Temming $\mathrm{N}$, Sønnesyne M, Røkenesse $H$, Yamasathiend A, Hogg P, Image quality and dose analysis for a PA chest $X$-ray: Comparisonbetween AEC mode acquisition and manual mode using the 10 kVp'rule'CRadiography 20 (2014) 339e345

${ }^{9}$ Tugwell J, Everton C, Kingmac A, Oomkens DM, Pereirad GA, Pimentinhad DB, Rouillere CAI, Stensrudf SM, Kjelle E, Jorge J, Hogg $P$, Increasing source to image distance for AP pelvis imaging Impact on radiation dose and image quality, Radiography 20 (2014) 351e355

${ }^{10}$ Mraity H, England A, Akhtara I, Aslam A, De Langed R, Momoniata H, Nicoulaze S, Ribeiro A, Mazhira S, Hogg P, Development and validation of a psychometric scale for assessing PA chest image quality: A pilot study, Radiography 20 (2014) 312e317

$11 \mathrm{Hogg}, \mathrm{P}$ and Lança, L 2014, Radiation dose and image quality optimisation in medical imaging, Open Source, University of Salford. Open Source, ISBN 978-1-907842-60-3

12 Hogg, P , Blakeley, C and Buissink, C, 2015, OPTIMAX 2015: multicultural team-based research in radiography, a holistic educational approach, University of Salford. Open Source, ISBN 978 -1- 9 07842-77-1

13 7. Hogg, P , Thompson-Hogg, R and Buissink, C, 2016, Optimising image quality for medical imaging, University of Salford, University of Salford. Open Source, ISBN 978 -1- 9 07842- $93-1$

${ }^{14}$ 8. Hogg, P, and Buissink, C OPTIMAX 2017 : radiation dose, image quality optimisation, the use of new technology in medical imaging, University of Salford, Salford, UK. Open Source, ISBN 978-1-912337-09-5

15 9. van der Heij-Meijer, A, Buissink, C and Hogg, P, 2018, OPTIMAX 2018 - a focus on education in radiology, University of Salford, Greater Manchester, UK. Open Source, ISBN: $978-1-912337-14-9$ 
${ }^{16}$ Brennan P, Currie G, Halkett G, Hogg P, Holden L, McEntee MF, Mitera G, Rainford L, Ying M.T.C., Guidance on good practice in authorship of journal publications, Radiography, Volume 22, Issue 3, August 2016, Pages 203-205 